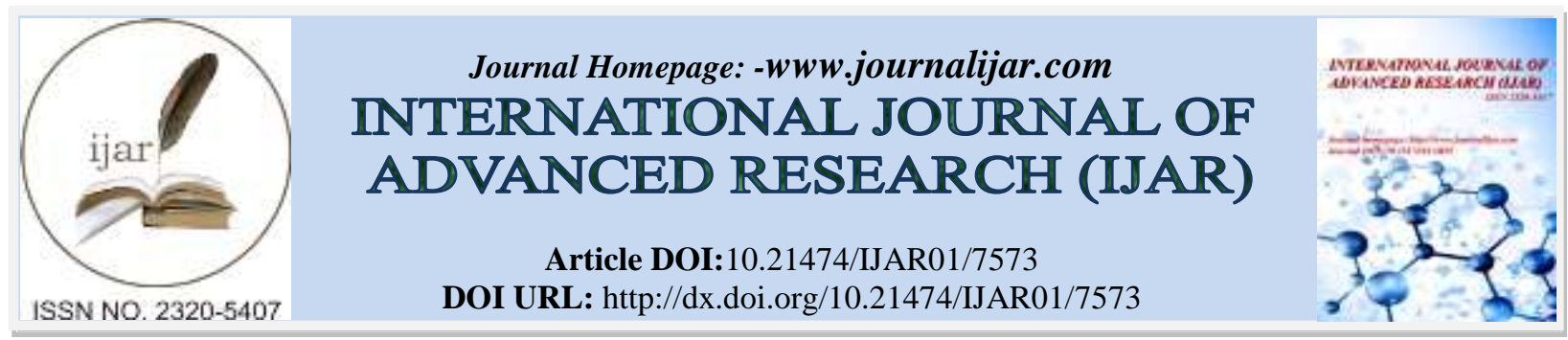

RESEARCH ARTICLE

\title{
TAKAYASU ARTERITIS PRESENTING WITH INTRACEREBRAL NON ANEURYSMAL BLEED IN YOUNG INDIAN WOMAN POSITIVE FOR HEPATITIS B.A CASE REPORT
}

\author{
Dr. Kamlesh Kumar Gupta ${ }^{1}$, Dr. Vinod kumar ${ }^{2}$ and Dr. Rohin ${ }^{2}$. \\ 1. Associate Professor, Department of medicine,King George Medical University,Lucknow. \\ 2. Senior Resident, Department of medicine,King George Medical University,Lucknow. \\ 3. Junior Resident, Department of medicine, King George Medical University,Lucknow.
}

\section{Manuscript Info}

Manuscript History

Received: 16 June 2018

Final Accepted: 18 July 2018

Published: August 2018

\begin{abstract}
:
Takayasu arteritis also known as pulseless disease is a chronic inflammatory vasculitis involving large vessels of aorta and its braches and is rarely associated with stroke of non aneurismal origin. Leucocytoclastic vasculitis and polyarteritisnodosa are common autoimmune extrahepatic associations seen with hepatits B virus. Rarely takayasu disease has been associated with hepatitis B virus infection. Here we present a young girl with hepatitis B positive acute viral hepatitis presenting with a non-aneurysmal intracerebral bleed. She was diagnosed with takayasu arteritis on clinical and radiographical basis. The occurrence of both disease in the same patient is quite a rare occurence.An association of hepatitis $\mathrm{B}$ induced autoimmune aorto-arteritis can be hypothesized for the same.
\end{abstract}

Copy Right, IJAR, 2018,. All rights reserved.

\section{Introduction:-}

Stroke is considered the third most common cause of death in India. Most common causes include atherosclerosis and cardioembolic disease and is considered as a disease of the old age. Patients suffering from stroke before the age of forty have a unique set of causes for most are mutations leading to hypercoagulability,some have potential specific therapy options which can help in better outcome in terms of morbidity and mortality. Systemic inflammatory conditions and autoimmune conditions should be considered in patients who suffer from cerebrovasccular accident before the age of forty as treatment of same has better outcome than idiopathic causes.

Vasculitis is a very common treatable leading to arterial ischemia and stroke.Takayasu arteritis is a chronic inflammatory disease of unknown origin which produces narrowing of aorta and its major branches. It commonly affects young Asian women and adolescent girls. It is the one of the commonest cause for renovascular hypertension in India. It is a granulomatous vasculitis involving large vessels and commonly involves aorta and its branches. Even without life threatening events like cerebrovascular accident and myocardial infarction it has been associated with severe morbidity and requires treatment as it has a chronic and relapsing course.Its exact cause remains idiopathic and rarely has it been associated with an infective etiology.

Hepatitis B infection is caused by virus of genus hepadnaviridae.It is commonly associated with acute viral hepatitis and chronic liver disease.Along with this, it also can present with extrahepatic manifestations associated with autoimmune conditions such as polyarteritis nodosa, autoimmune reactions and autoimmune anemia. 
Here we present a young patient with hepatitis B positive who was admitted with intracerebral bleed and she was subsequently diagnosed with takayasu arteritis. The occurrence of both disease in the same patient is quite rare however an association of hepatitis B induced autoimmune aorto-arteritis can hypothesized for the same.

\section{Case report-}

A twenty year old female was admitted to emergency in a state of altered sensorium with decreased movement of left side of the body since 1 day. Her attendants stated that she had suffered from multiple bouts of vomiting which was followed by an episode of generalized tonic clonic seizures. She had been in a state of altered sensorium since then. There was no history of fever, loose stools, head trauma, or excessive bleeding prior to this episode. She was not a known hypertensive nor was on any hypertensive medications. She had no family history of cardiac, autoimmune or cerebrovascular disease. She was born of a non consanguineous marriage and was the younger of two siblings with elder sibling showing no central nervous system symptoms. She had a Glasgow Coma Score of E2V1M5 with bilateral small size pupil with sluggish reactivity and no features of cranial nerve palsy that could be clinically established. She had stable vitals with asymmetrical blood pressures of 130/80 and 100/70 and 170/100 and 160/90 in right upper limb, left upper limb, right lower limb and left lower limb respectively. Her motor examination revealed left sided hemiparesis with spasticity of left upper and lower limb and normal tone on right side upper and lower limbs Fundus examination showed no hemorrhages. No carotid bruit was appreciatable.A CT scan was requested which revealed an intracerebral bleed with perifocal edema in right corona radiate, gangliocapsular and parieto-temporal region with intraventricular extension.Patient was further evaluated for possible causes for stroke.

Her complete blood picture and renal function test were within normal limits.Her liver function test was deranged with-Total Bilirubin-3mg/dl, Direct Bilirubin-2.11mg/dl,SGOT-151U/L,SGPT-156U/1,ALP-452U/1,SPRO-6.2g/dl SALB-4.1g/dl and ultrasound of abdomen revealed mild hepatomegaly.Her ESR was $4 \mathrm{~mm} / \mathrm{hr}$ and CRP was $8 \mathrm{mg} / \mathrm{dl}$.Her echocardiography showed no abnormalities or clots with preserved ejection fraction. In view of asymmetrical radial pulsations during routine blood pressure monitoring, a revised provisional diagnosis of takayasu arteritis was kept and CT angiography of aortic vessels was ordered. Her CT angiography revealed- mild circumferential mural thickening in aorta at L2-L3 level along with moderate circumferential mural thickening at origin of superior mesenteric artery and involving ostium of bilateral renal artery and ostium of right renal artery for $1 \mathrm{~cm}$ and left renal artery for 6.5 centimeters.MRV showed a hypoplastic left transverse sinus while MRA revealed normal flow within ACA,MCA and circle of willis with an non aneurismal right basal ganglia hemorrhage and fetal origin of left PCA. Patient was also positive for hepatitis B antigen by ELISA with active replication of virus with HbeAg positive and HBV DNA $3.6 \times 10^{5} \mathrm{IU} / \mathrm{ml}$.In absence of other causes of vasculitis and inflammatory markers she was diagnosed with takayasu disease and started on antiviral medications and steroids. Patient made full recovery and regained a significant degree of function except for vocalization and with GCS E3V1M5 was discharged on tapering dose of steroids with Tab Tenofovir 300mg OD and antiepileptics. She came for follow up with improved GCS of E4V1M6 and declining viral titres.

\section{Discussion:-}

Takayasu arteritis also known as pulseless disease is a chronic inflammatory vasculitis involving large vessels of aorta and its braches leading to severe narrowing and ischemic features ${ }^{[1]}$.Although it can present in any age group and sex, it is commonly seen in young females ${ }^{[2]}$.It affects small vessels and causes cutaneous manifestations like erythema nodosum, along with necrotizing vasculitis occurring in up to $12 \%$ of patients. These manifestations improve and disappear with disease remission ${ }^{[3]}$. Takayasu disease manifesting with neurological complications is rare and cerebrovasccular events are even rarer ${ }^{[4]}$. Strokes are uncommon in takayasu arteritis.Ischemic strokes occur present late due to extensive collateral development while intracerebral bleed of aneurismal origin occur earlier due to defective media of vessel wall and prolonged uncontrolled hypertension. Secondary hypertension in Takayasu can be held responsible for a potential mechanism of intracerebral bleed ${ }^{[5]}$. While another possible mechanism is vessel wall thinning secondary to inflammation and fibrosis of vessel walls ${ }^{[6]}$.

In our case the young female was diagnosed with non aneurismal bleed with a Magnetic Resonance Imaging and MR angiography of cerebral vessels while Computerized tomography angiography of large vessels abdominal vessels revealed findings suggestive of takayasu arteritis. A hemorrhagic stroke of non aneurysmal origin should invite a search for a secondary cause in these young patients. This case is an unusual presentation of a rare disease as the patient presented with non aneursymal bleed rather than occlusive vascular disease. Vasulititic disorders are idiopathic or are caused by complex interactions of the environment with organisms in genetically susceptible 
individual leading to arteritis Leucocytoclastic vasculitis and polyarteritis nodosa are seen with hepatits B virus but the association with Takayasu's arteritis is new ${ }^{[7]}$. In our knowledge, only two documented cases of Takayasu's arteritis in association with acute hepatitis B have been published. We hypothesize that hepatitis B virus is capable of being a potential trigger for takayasu arteritis or takayasu should be considered as an extrahepatic manifestation of hepatits B virus ${ }^{[8]}$ Infective causes induce autoimmunity via immune complex formation and immune dysregulation and even molecular mimicry.This case report emphasizes on evaluation young patients with stroke for vasculitis as a provisional cause and evaluation of hepatitis virus panel as in such patients. We should evaluate for all possible treatable causes including the rare ones which may be treated or at least modified timely as they have a significant bearing on morbidity and mortality of the patient.Increased awareness of this possibility will lead to more frequent evaluation for hepatitis in patients with Takayasu's arteritis which may increase the number of reported cases with this rare combination.

In conclusion we would like to suggest evaluation of patients presenting with cerebrovasccular accident in young age for vasculitis and emphasize on assessing patients with vasculitis for infectious causes which are potent riggers for autoimmune reaction.

\section{References:-}

1. .M.D.EuloLupi-Herrera M.D.GustavoSánchez-Torres et al-Takayasu's arteritis. Clinical study of 107 cases.

2. ROSSO F. V., VERLATO F., SCARPA R., ANDREOZZI G. M.- Takayasu arteritis in a 66-year-old caucasian woman. Minerva Cardioangiol., 2002, 50 (3) : 259-62

3. S L Johnston, R J Lock, and M MGompels-Takayasu arteritis: a review-J ClinPathol. 2002 Jul; 55(7): 481-486.

4. Park MC M $^{1}$, Lee SW, Park YB, Chung NS, Lee SK-Scand J Rheumatol. 2005 Jul-Aug;34(4):284- Clinical characteristics and outcomes of Takayasu's arteritis: analysis of 108 patients using standardized criteria for diagnosis, activity assessment, and angiographic classification.

5. KRISHNA M. V., RUDRESH, NAMRATHA S. -Takayasu arteritis - Stroke as an Initial presentation. J. Indian Acad. Clin. Med., 2004, 5 (3) : 274-276.

6. Hyun SJ, Hwang SN, Nam TK, Park SW, Byun JS - 4 Neurol Med Chir (Tokyo). 2011;51(2):119-22Takayasu's arteritis complicated with subarachnoid hemorrhage and hematomyelia--case report.

7. TrepoC, Guillevin L et al Polyarteritisnodosa and extrahepatic manifestations of HBV infection: the case against autoimmune intervention in pathogenesis.

8. Etgen T, Winbeck K, Conrad B, Sander D-J Neurol. 2003 Feb;250(2):226-9.-Hemiballism with insular infarction as first manifestation of Takayasu's arteritis in association with chronic hepatitis B. 